www.jmscr.igmpublication.org

Impact Factor 5.84

Index Copernicus Value: 71.58

ISSN (e)-2347-176x ISSN (p) 2455-0450

crossref DOI: _https://dx.doi.org/10.18535/jmscr/v5i10.171

Journal Of Medical Science And Clinical Research

IGM Publication

An Official Publication of IGM Publication

\title{
Study of Outcome, Morbidity and Mortality of Transurethral Resection of Prostate in Patients with Renal Insufficiency Not Requiring Dialysis
}

\author{
Authors \\ Selvakumar Soman ${ }^{1}$, Kannan Subramanian Ramasamy ${ }^{2}$ \\ ${ }^{1,2}$ Department of Urology, Government Kanyakumari Medical College, Nagercoil, Tamilnadu, India
}

\begin{abstract}
Introduction: Benign Prostate Hyperplasia (BPH) is a common disease in adult men and its incidence is age related. Attending to high prevalence of $B P H$ in older men with renal insufficiency it is invaluable to take into consideration the relationship between these two clinical entities. The purpose of this study was to determine the incidence of renal failure associated with BPH, effect of TURP in the morbidity and mortality of patients with renal failure. The aims of this study are to study the prevalence of co-morbid factors in patients with Benign prostatic hyperplasia and non dialysis requiring renal insufficiency, Study of treatment outcome following transurethral resection of prostate (TURP) with non dialysis requiring renal failure and to study of complications associated with TURP in these patients.

Materials and Methods: This is a Prospective study conducted between JAN 2015 to AUG 2017 in Department of Urology, Government Kanyakumari Medical College, Nagercoil, Tamilnadu, India. This is a study of 40 cases of Benign prostatic hyperplasia in normal and in patients with non dialysis requiring renal failure who underwent TURP. The inclusion criteria being all patients with Non dialysis requiring Renal Dysfunction associated with BPH. The exclusion criteria being histologically proven malignant prostatomegaly and patients with end stage renal disease requiring hemodialysis.

Results and Conclusion: The incidence of renal failure associated with BPH in our study was about 12.5\%. After excluding patients with prostatic malignancy, patients needing dialysis, the study group constituted 5\%. There was no significant variation in preoperative and postoperative levels of serum sodium, potassium levels in patients with nondialysis requiring renal failure (S.creatinine less than 3), when compared to normal patients. Complications of TURP in patients who had nondialysis requiring renal failure, was on the higher side. Bleeding as a complication requiring blood transfusion was noted in $20 \%$ of patients compared to normal patients. But overall complication rate was not statistically significant. This can be attributed to either small sample size, improvement in instruments like continuous flow resectoscope, use of non hemolytic irrigation solutions can be a factor. The outcome following TURP was successful with restoration in normal renal function and normal voiding pattern in majority of patients and it was further noted that the successful outcome of TURP in these patients were influenced by various factors such as age, duration of symptoms, severity of lower urinary tract symptoms, severity of renal failure at the time of presentation. The size of Prostate gland had no correlation with the final outcome.

Keywords: Benign prostatic hyperplasia, Renal failure, Chronic kidney disease, Transurethral resection of prostate.
\end{abstract}




\section{Introduction}

Benign Prostate Hyperplasia (BPH) is a common disease in adult men and its incidence is age related. Prevalence of BPH is approximately $25 \%$ in men aged 40 to 49 years, $50 \%$ in men aged 50 to 59 years and $80 \%$ in men aged 70 to 79 years. ${ }^{1}$ Renal failure and symptomatic $\mathrm{BPH}$ are two common health problems; they usually co-exist in $5.9-13.6 \%$ of the male population over 50 years of age. Actually going by the natural history of the disease and its progression with relation to $\mathrm{BPH}$ and its complications, it is noted that $13.6 \%$ of patients who presented to undergo TURP were in renal failure. It is usually not clear in this group of patients whether the reason for renal insufficiency is or is not BPH. However, it has been reported in some studies that the incidence of diabetes mellitus and hypertension is higher in patients with renal failure (RF) and lower urinary tract symptoms (LUTS) due to BPH. On the other hand, it is known that due to chronic urinary obstruction, BPH can lead to renal failure and even death occasionally. The main constant indication for BPH surgery has been medical treatment-refractory moderate or severe Lower urinary tract symptoms; but definite surgical indications usually include upper urinary tract deterioration. Renal failure increases the risk in TURP, so there is a tendency for avoiding the surgery till there is a detection of an absolute indication occurs. But these studies are based on data from two or three decades ago not representing current practice. As we understand that these patients with $\mathrm{BPH}$ whether symptomatic or asymptomatic, if left untreated may present with renal failure which could be chronic or acute. Despite the many possible causes of renal failure in elderly patients, the common causes were BPH (38\%), neurogenic bladder (19\%), obstructive pyelonephritis $(15 \%){ }^{2}$ While the underlying mechanism for developing renal failure associated with BPH is likely multifactorial and co-morbid factors in elderly men may contribute to renal impairment, we wanted to evaluate the incidence of BPH with renal failure at our institute. TURP remains the gold standard surgical procedure for treatment of these cases. However, patients in renal failure have an increased risk for complications after TURP compared with patients with normal renal function, so we wanted to study the treatment outcome and complications associated with its management. Attending to high prevalence of BPH in older men with CKD it is invaluable to take into consideration the relationship between these two clinical entities. However, despite the high prevalence of renal failure and $\mathrm{BPH}$ in elderly men, there is limited knowledge on the association between these two conditions, there is very little information in the literature regarding the role of only $\mathrm{BPH}$ as a causative factor in causing renal failure and its treatment outcome. The purpose of this study was to determine the incidence of renal failure associated with BPH, effect of TURP in the morbidity and mortality of patients with renal failure.

\section{Aims and Objectives}

1. To study the prevalence of co-morbid factors in patients with $\mathrm{BPH}$ and non dialysis requiring renal insufficiency.

2. Study of treatment outcome following the surgical management of BPH with non dialysis requiring renal failure.

3. Study of complications associated with TURP in these patients

\section{Review of Literature}

Epidemiology of Benign prostatic hyperplasia: BPH occurs with increased growth of non malignant tissue of prostate which surrounds urethra, it narrows the lumen of urethra and subsequently gives rise to symptoms. ${ }^{63}$ Diagnosis of $\mathrm{BPH}$ done conclusively on histological evaluation of prostate. Histological evaluation is by taking prostate by transurethral resection or Trans rectal ultrasound guided or by doing autopsy. But other measures, namely symptomatology, obstruction of bladder with associated enlarged prostate are used to mark 
BPH. Because of this, the end point of $\mathrm{BPH}$ becomes difficult to assess. The prevalence of $\mathrm{BPH}$ is calculated by taking histological part (assessed by autopsy) or clinically. (3) No men $30 \mathrm{yrs}$ and younger had evidence of BPH and the peak of prevalence increased along with each age group, ultimately reaching $88 \%$ in men with eighties. ${ }^{4}$ Histologically, hyperplasia of prostate is seen in $8 \%$ men of age 31-40. Whereas it increases to $90 \%$ of men in ninth decade. ${ }^{4,7}$ In the setting of BPH, untreated chronic kidney disease (CKD) can result in ESRD requiring dialysis or kidney transplantation.

\section{Relationship between benign prostatic hyperplasia and Chronic Kidney Disease:} Etiology of BPH is largely unknown, but from clinical practice and studies, natural history of hyperplasia of prostate leads to urinary obstruction, landing in deterioration of renal function with time. Both $\mathrm{BPH}$ and CKD are commonly prevalent in ageing male.

Aspect of Treatment: Patients with mild symptoms are managed by watchful waiting, patients with moderate symptoms should receive pharmacotherapy and patients with severe bother benefit the most from surgical management. So, a man with preoperative IPSS more than17, has $87 \%$ chance of having symptom reduction. ${ }^{52}$

We have to identify a group of patients who are at increased risk of progression (e.g. age, symptoms, Prostate specific antigen level, Qmax, volume of prostate and post-void residual urine). Here we have to give early preventive treatment. ${ }^{53,50}$ Because, a higher frequency of kidney failure in patients presenting for prostate surgery than for non prostate surgery has been shown, and several studies have shown improvement in kidney function after prostatectomy. ${ }^{21}$

Emergency situations: Patients who present to the casualty, with bladder outlet obstruction and high serum Creatinine, they should first be put in a urethral catheter and subsequently they need to be evaluated to distinguish between, whether it is an acute and chronic renal failure. Hospitalization is required in these cases. If hydrouretronephrosis and azotaemia persists despite decompressing the bladder, we should suspect an ureterovesical junction obstruction and the next step would be bilateral percutaneous nephrostomy or bilateral double $\mathrm{J}$ stents if possible, these are done for temporarily drainage. Patients further may need urgent hemodialysis. Ureteroneocystostomy after a prostate ablation may be adequate for definite ureterovesical junction obstruction resolution.

Benign prostatic hyperplasia - Medical treatment: Medical approaches are not used to treat if complications are associated with $\mathrm{BPH}$ (one of them is chronic kidney disease). They are used for Lower urinary tract symptoms relief and for preventing the progression of benign prostatic hyperplasia (especially 5 alpha reductase inhibitors - 5- ARI). It is also useful in preventing BPH complications such as chronic kidney failure. However, they can't revert CKD secondary to BPH. Surgical treatment: Surgical treatment is mainly offered to men developing complications from BPH. Health Care Policy and Research agency and International Consensus Guidelines, recommend surgery if patient has 1 . Refractory urinary retention (patient failing at least one catheter removal attempt) 2. Following conditions secondary to benign prostatic hyperplasiarecurrent Urinary tract infection, bladder stones, recurrent gross hematuria, renal insufficiency, large bladder diverticula. ${ }^{40}$ Some studies suggest that dialysis dependent patients may recover renal function up to a year after prostatic surgery. Here efforts should be made to identify and treat BPH in patients under dialysis. Erectile dysfunction in about $4 \%$ to $10 \%$ and urinary incontinence in $0.5 \%$ to $1.5 \%$ can develop in postoperative period. 54,42 Recurrence of BPH following surgery at five years is about $2 \%$ to $10 \%$. Complications: Bleeding Arterial bleeding is more noticed in cases with preoperative infection, retention of urine due to gland getting congested. Antiandrogen preoperatively can help in decreasing bleeding. Venous bleeding due to perforation of capsule and opening of venous sinusoid during surgery. The amount of intraoperative bleeding 
usually depends on size of prostate gland and amount resected. Extravasation If bladder neck division occurs or capsule perforated, extravasation occurs. It is usually extra peritoneal, but if bladder injured or diffusion occurs in large volume, it can become intra peritoneal. Injury to Ureteric orifices: It can occur during large median lobe resection where it becomes difficult to identify ureteric orifice. Treatment depends on severity. External sphincter injury: Injury occurs mostly at ventral area (at $12^{\prime} 0$ clock position) because we cannot visualize verumontanum. But if verumontanum is already resected, the sphincter injury risk increases.

\section{Postoperative complications ${ }^{57}$ Bladder} tamponade Evacuation of clots due to recurrent or persistent bleeding or reintervention occurs in $1.3-5 \%$ patients. Changing of colour from clear to red intermittently in irrigation suggests arterial bleeding, whereas venous bleeding usually results in an irrigation fluid continuously showing dark red colour. Infection The infection rate is usually low .Risk factors for infection: Preoperative bacteruria, Duration of procedure exceeding 70 min, Tamponade evacuation, and Preoperative stay longer than two days. Retention of Urine: It occurs in 3-9\% of patients. Mostly due to detrusor failure rather than, incomplete resection. It is advised not to go for resurgery till prostatic fossa is healed; exception is if transrectal ultrasound showing significant tissue likes ventile effects. Early incontinence occurs in $30-40 \%$ of patients, but late iatrogenic stress incontinence occurs in less than $0.5 \%$. Urethral stricture ${ }^{58}$ Literature suggests $2.2 \%$ to $9.8 \%$ occurrence and no relationship to time present. The locations and reasons are - Meatal strictures occurs due to inappropriate size of the instrument and the diameter of meatus, Bulbar strictures are due to inadequate isolation by the lubricant, so monopolar current leaks. We need to apply gel in urethra and along resectoscope shaft. Reapply the gel if procedure is long. Avoid high cutting current. Perform internal urethrotomy if meatus narrowed or stricture present. Bladder neck stenosis It is around $0.3 \%$ to $9.2 \%$ in incidence, more with lesser than $30 \mathrm{~g}$ gland resection. Prophylactic bladder neck incision while concluding procedure may decrease incidence. Once it develops, treatment is by incision by laser or electrical current. Retrograde ejaculation Avoiding of tissue around bladder neck leads to reduced incidence. Especially in younger patients, try medical treatment. Transurethral incision leads to reduced incidence. Erectile dysfunction Around $3.4 \%$ to $32 \%$ develop erectile dysfunction. High frequency current applied close to the capsule damages neurovascular bundle. Recurrent Benign Prostatic Hyperplasia Usually due to insufficient resection or natural course of disease, but it is lesser with TURP than Transurethral microwave therapy and Trans urethral needle ablation. TUR syndrome $^{59}$ it is around $2 \%$. It is due to fluid intoxication, serum sodium level less than 130nmol/L. Large glands, venous sinus opening, prolonged resection time, and smoking history increase risk. Post-obstructive diuresis Marked natriuresis along with water excretion characterizes this disorder. In addition other serious electrolyte disorders such as hypokalemia, hyponatremia and hypomagnesemia can occur. The etiology is multifactorial, related to fluid and urea accumulation in obstruction and tubular resistance to aldosterone and antidiuretic hormone. Treatment by fluid replacement with $0.45 \%$ saline, at a rate slightly less than urine output and replacement of electrolytes as they are needed.

Renal recovery ${ }^{61},{ }^{62}$ Complete or prolonged partial urinary tract obstruction leads to tubular atrophy and eventually irreversible renal injury. Prognosis after relief of obstruction is depends on duration, severity of obstruction. Complete recovery of glomerular filtration rate occurs if relieved within one week, but little or no recovery, occurs after 12 weeks. However, measurement of the Glomerular Filtration Rate probably overestimates the true degree of recovery. In a rat model in which complete unilateral ureteral obstruction was induced for 24 hours, 
approximately 15 percent of nephrons were nonfunctional as late as 60 days after release, a presumed reflection of irreversible injury. Despite this nephron loss, the Glomerular filtration rate can return to normal because of hypertrophy and hyper filtration in the remaining functional nephrons. It is likely that a similar process of compensatory hypertrophy occurs in human obstruction, as it has been demonstrated in other diseases such as lupus nephropathy. The course of partial obstruction is less predictable. It clearly depends on the severity and duration of the obstruction, as well as other potential complicating factors, such as hypertension, infection, or pre-existing renal disease.

Functional recovery ${ }^{61,}{ }^{62}$ Radionuclide scanning and renal ultrasonography have been used in an attempt to predict the likelihood of functional recovery. Adverse prognostic findings thought to be indicative of severe and usually irreversible disease include total nonvisualization on renal scan and marked cortical thinning on ultrasonography. But, these findings may not be useful in the individual patient, since their presence does not preclude substantial return or even near normalization of the GFR following release of the obstruction. Most of the functional recovery will usually be seen in the first 7 to 10 days after relief of the obstruction. However, some patients with severe renal failure may, after the obstruction is relieved, require dialysis for a period of weeks until sufficient improvement occurs to allow dialysis to be discontinued. Only partial recovery is seen in this setting with the plasma Creatinine concentration generally stabilizing at a value above $3 \mathrm{mg} / \mathrm{dL}$ (264 $\mu \mathrm{mol} / \mathrm{L})$.

\section{Materials and Methods}

Study Design: Prospective study Duration: January 2015 to August 2017

Setting: Department of Urology, Government Kanyakumari Medical College, Nagercoil, Tamilnadu, India. This is a clinical study of 40 cases of BPH in normal and in patients with non dialysis requiring renal failure who underwent TURP.

\section{Patient Selection}

Inclusion Criteria All patients with Non dialysis requiring Renal Dysfunction associated with Benign Enlargement of Prostate in the Department of Urology in our institute.

Exclusion Criteria Histologically proven malignant prostatomegaly, Patients with end stage renal disease requiring hemodialysis.

Data Collection This is a clinical study of 40 cases of BPH who underwent surgical therapy Transurethral resection of prostate in our institute, out of which 20 patients presented with elevated renal parameters. The screening was done by selecting all the patients presenting with $\mathrm{BPH}$ (350 patients) at our institute during the study period, out of which patients who had associated renal failure on the basis of serum Creatinine value were selected. Serum Creatinine level of greater than $1.4 \mathrm{mg} / \mathrm{dl}$ was taken as criteria to determine the presence of renal failure. Among the patients who had BPH with renal failure cases which satisfied the inclusion criteria (20 patients) were selected and rest of the cases i.e. cases which required dialysis, prostatic malignancy, and causes of obstructive uropathy other than BPH were filtered out. All the patients in the study group presented to our institute with severe obstructive voiding symptoms including retention of urine who underwent urethral catheterization and residual urine were measured. All the patients underwent ultrasound abdomen, some of the patients before and some after catheterisation. Serum Prostate Specific Antigen (PSA) levels were done only in patients with suspicious finding on digital rectal examination. After the stabilization of renal function (RFT) all the patients underwent diagnostic Cystoscopy followed by TURP. Indwelling 22 Fr three way Foley's catheter was inserted which was removed on 3rd post operative day. Patients who went for retention after catheter removal were re catheterised and check cystoscopy done later to rule out the possible obstructive causes of 
retention. Patients who voided successfully were discharged. Histology of the resected prostate confirmed benign prostatic hyperplasia in all cases. In the post operative period Serum Creatinine estimation was done on 2nd, 7th day and at 6 weeks. Ultrasound was done 6 weeks post operatively. Patients with non dialysis requiring renal insufficiency and normal patients were grouped as groups 1 and 2, respectively. Patient age, comorbid diseases, IPSS, residual urine volume, prostate volume, urea, creatinine (at presentation, post catheterisation), Sodium, potassium, haemoglobin levels recorded preoperatively. Bleeding time and clotting time done preoperatively in all patients to rule out any coagulation abnormality. If any patient in group 1 shows a drop of S.creatinine below 1.4 in the post catheterisation setting, they were shifted to group 2 along with normal patients. Transurethral resection of prostate was performed using a 27 French continuous flow Storz resectoscope and $1.5 \%$ glycine solution. Regional anaesthesia was employed. Early postoperative values of haemoglobin, $\mathrm{Na}, \mathrm{K}$, and Creatinine levels which were measured 24 hours after the operation were recorded. The need for blood transfusion and presence of a TUR syndrome were also evaluated. The catheters of the patients were removed in 3rd Postoperative day after the urine became clear.

\section{Data Analysis}

\section{Statistical Methods Applied}

Frequencies The Frequencies procedure provides statistics and graphical displays that are useful for describing many types of variables. The Frequencies procedure is a good place to start looking at your data.

Descriptives The Descriptives procedure displays univariate summary statistics for several variables in a single table and calculates standardized values (z scores). Variables can be ordered by the size of their means (in ascending or descending order), alphabetically, or by the order in which you select the variables (the default).
Chi-Square Test The hi-Square Test procedure tabulates a variable into categories and computes a chi-square statistic. This goodness-of-fit test compares the observed and expected frequencies in each category to test either that all categories contain the same proportion of values or that each category contains a user-specified proportion of values.

Crosstabs (Contingency coefficient test) The Crosstabs procedure forms two-way and multiway tables and provides a variety of tests and measures of association for two-way tables. The structure of the table and whether categories are ordered determine what test or measure to use.

Paired samples t test The Paired-Samples T Test procedure compares the means of two variables for a single group. It computes the differences between values of the two variables for each case and tests whether the average differs from 0 .

Independent-Samples $\mathbf{T}$ Test The IndependentSamples $\mathrm{T}$ Test procedure compares means for two groups of cases. Ideally, for this test, the subjects should be randomly assigned to two groups, so that any difference in response is due to the treatment (or lack of treatment) and not to other factors. All the statistical calculations were done through SPSS 16.0 (2007) for windows.

Multinomial Logistic Regression Multinomial Logistic Regression is useful for situations in which you want to be able to classify subjects based on values of a set of predictor variables.

Pearson's correlations coefficient The Bivariate Correlations procedures computes Pearson's correlations coefficient. Correlations measure how variables or the Rank orders are related. The statistical operations were done through SPSS 16.0 (2007) for windows and EPIINFO software 


\section{JMSCR Vol||05||Issue||10||Page 29480-29498||October}

\section{Observation and Results}

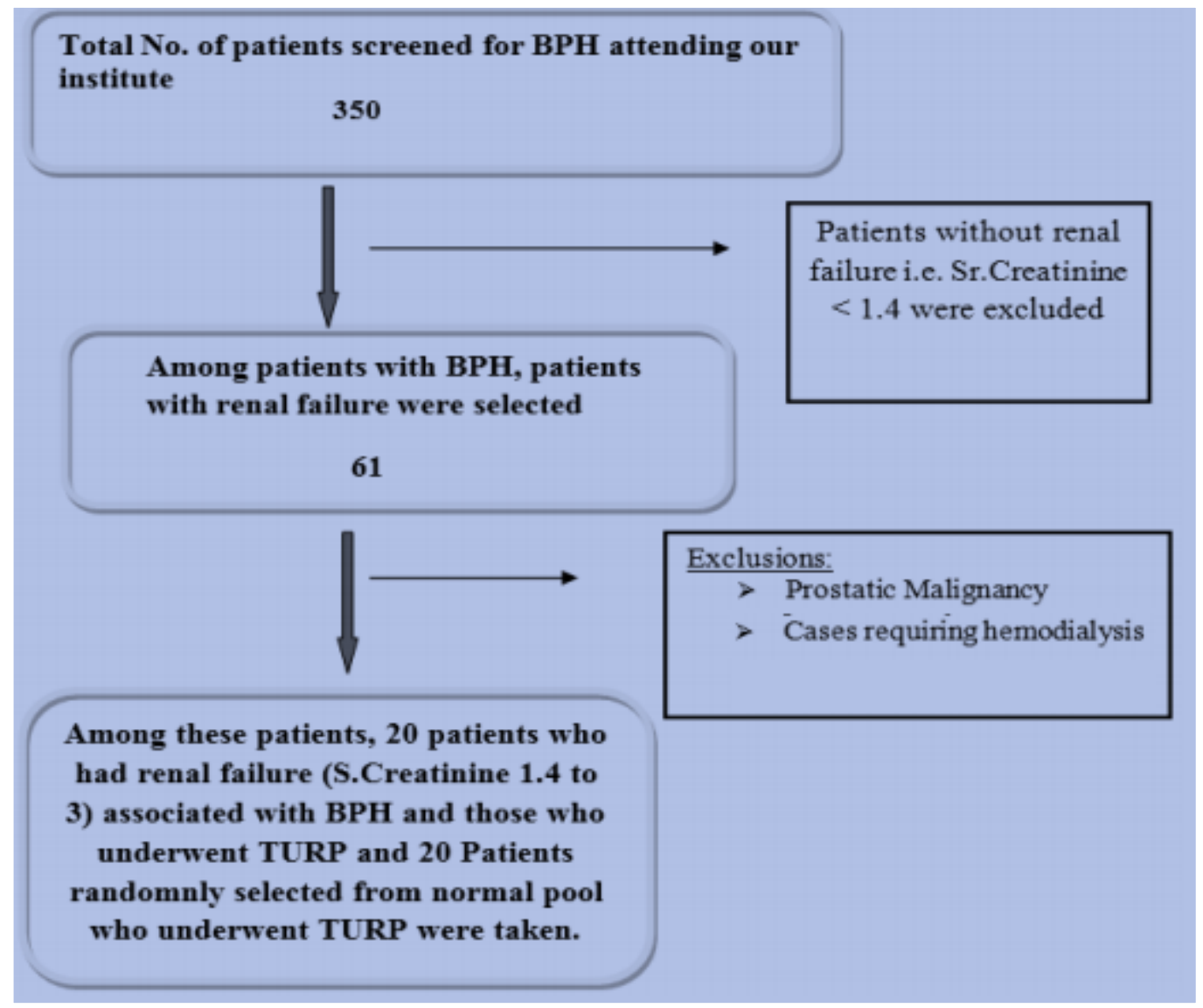

In our study total of 350 patients at our institute were screened during the study period and 20 of those patients who satisfied the inclusion criteria were included in the study group. The observation and results of the study were as follows.

\section{Descriptive Study}

Table 1 Age Distribution of study population: Group 1

\begin{tabular}{|l|c|c|}
\hline Age (in yrs) & No. of patients & Percentage \\
\hline $51-60$ & 5 & $25 \%$ \\
\hline $61-70$ & 11 & $55 \%$ \\
\hline $71-80$ & 4 & $20 \%$ \\
\hline $81-90$ & 0 & $0 \%$ \\
\hline Total & 20 & $100 \%$ \\
\hline
\end{tabular}

\begin{tabular}{|l|c|c|c|c|c|}
\hline & Group & N & Mean & $\begin{array}{c}\text { Std } \\
\text { Deviation }\end{array}$ & $\begin{array}{c}\text { P } \\
\text { Value }\end{array}$ \\
\hline \multirow{2}{*}{$\begin{array}{l}\text { Age in } \\
\text { years }\end{array}$} & Group I & 20 & 65.00 & 5.620 & 0.620 \\
\cline { 2 - 5 } & Group II & 20 & 64.00 & 5.959 & \\
\hline
\end{tabular}

Age distribution pattern in Group 1 patients In a total of 20 patients in Group 1, the youngest was 55 years and oldest was 75 years with a mean age of 64 years and standard deviation of 5.62 with the predominant age group 61-70 years
Table 2 Age Distribution of study population: Group 2

\begin{tabular}{|l|c|c|}
\hline Age (in yrs) & No. of patients & Percentage \\
\hline $51-60$ & 8 & $40 \%$ \\
\hline $61-70$ & 7 & $35 \%$ \\
\hline $71-80$ & 5 & $25 \%$ \\
\hline $81-90$ & 0 & $0 \%$ \\
\hline Total & 20 & $100 \%$ \\
\hline
\end{tabular}

Age distribution pattern in Group 2 patients: In Group 2, the youngest patient was 52 years and oldest patient was 76 years with a mean of 64 years with a standard deviation of 6.95 .

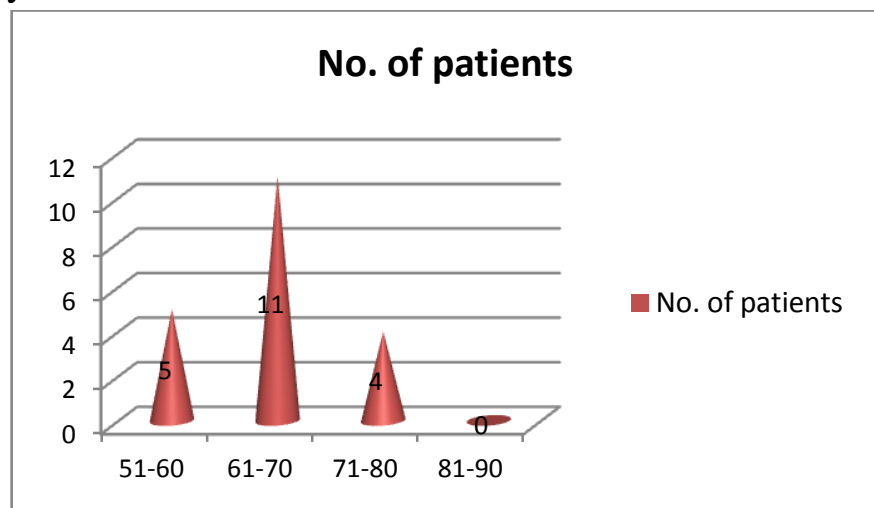

Figure 1 - Frequency distribution of population in Group 1 


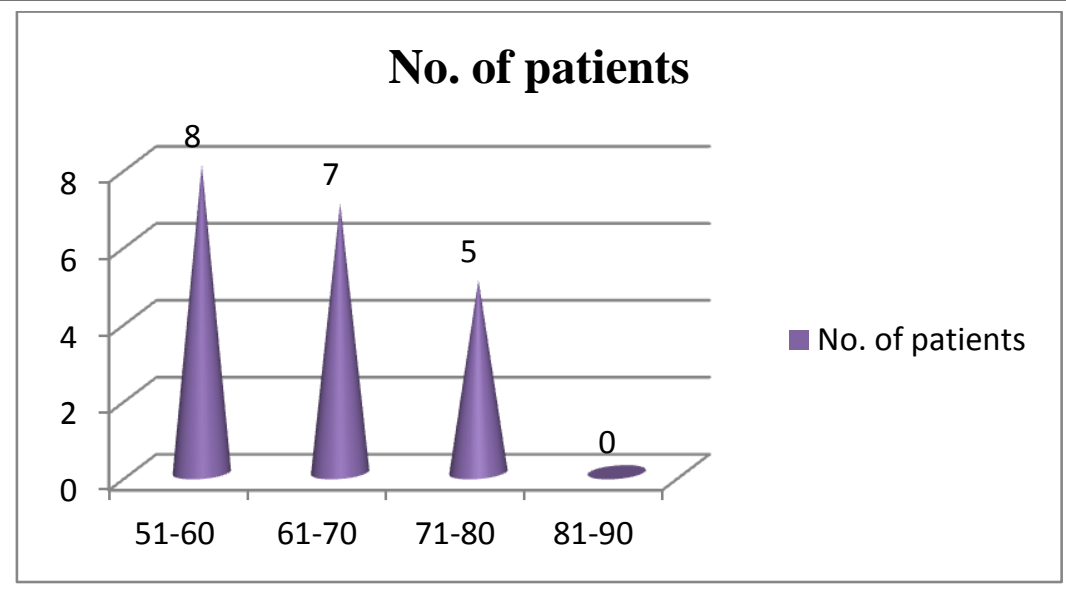

Figure 2 - Frequency distribution of population in Group 2

Table 3 - Symptom score

\begin{tabular}{|l|c|c|c|c|c|}
\hline \multicolumn{6}{|l|}{ Symptom score and Quality of Life } \\
\hline IPSS & $\mathrm{N}$ & Minimum & Maximum & Mean & Std. Deviation \\
\hline Group 1 & 20 & 20 & 24.95 & 1.986 & .444 \\
\hline Group 2 & 20 & 20 & 24.65 & 1.899 & .425 \\
\hline
\end{tabular}

All the patients had severe IPSS (majority had obstructive symptoms) with a mean score of 24.95 in Group 1 and 24.65 in Group 2, minimum and maximum score of 20 and 25 respectively with a standard deviation of 1.98. On analysis of IPSS score it was found that mean obstructive symptoms score was 14.3 as compared to the mean irritative symptoms score of 10.5 .

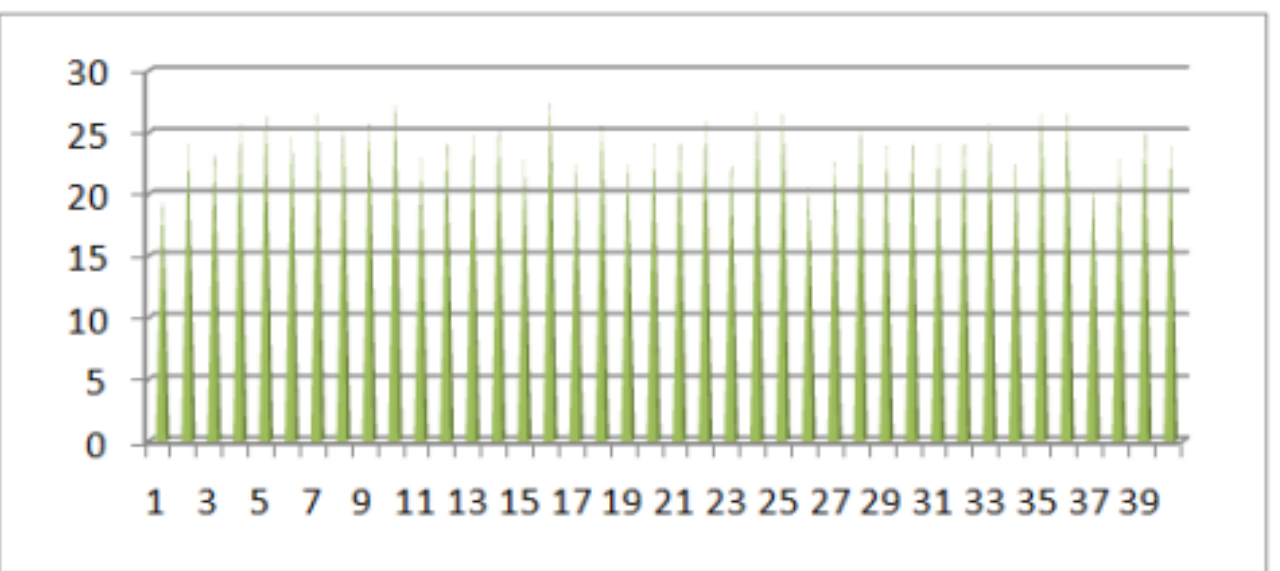

Figure 3. IPSS score in this study population

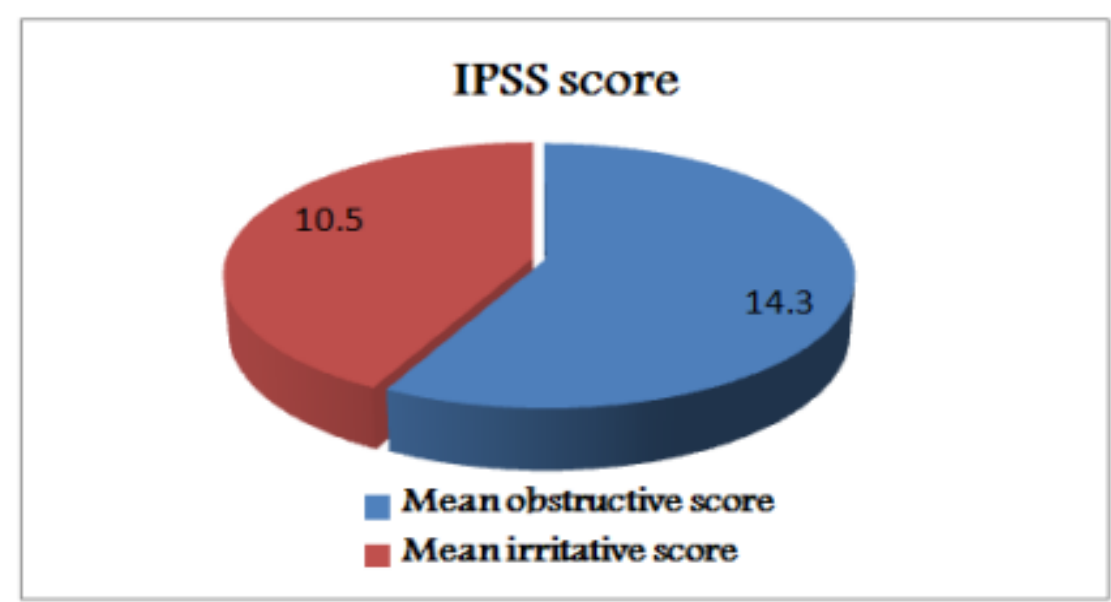

Figure 4. IPSS score (obstructive vs. irritative score) 


\section{JMSCR Vol||05||Issue ||10||Page 29480-29498||October}

\section{Comorbities associated with groups}

In Group 1, out of 20 patients who presented, nine people had co morbidities; where as in group two eight people had co morbidities. The difference between these two groups was not significant.

Table 4 - Correlation of co morbidities both within the group and between the two groups

\begin{tabular}{|c|c|c|c|c|c|}
\hline \multicolumn{2}{|c|}{} & \multicolumn{2}{c|}{ GROUP } & TOTAL \\
\cline { 3 - 5 } \multicolumn{2}{|c|}{} & Group I & GROUP II & \\
\hline Co morbidities & NIL & Count & 11 & 12 & 23 \\
\hline & & \% within Co morbidities & 47.8 & 52.2 & 100.0 \\
\hline & & \% within Group & 55.0 & 60.0 & 57.5 \\
\hline & HT & Count & 3 & 3 & 6 \\
\hline & & \% within Co morbidities & 50.0 & 50.0 & 100 \\
\hline & & \% within Group & 15.0 & 15.0 & 15 \\
\hline & DM & Count & 5 & 4 & 9 \\
\hline & & \% within Co morbidities & 55.6 & 44.4 & 100.0 \\
\hline & & \% within Group & 25.0 & 20.0 & 22.5 \\
\hline & Both & Count & 1 & 1 & 2 \\
\hline & & \% within Co morbidities & 50.0 & 50.0 & 100.0 \\
\hline & & \% within Group & 5.0 & 5.0 & 5.0 \\
\hline \multirow{2}{*}{ Total } & & Count & 20 & 20 & 40 \\
\cline { 3 - 5 } & & \% within Co morbidities & 50.0 & 50.0 & 100.0 \\
\cline { 3 - 5 } & \% within Group & 100.0 & 100.0 & 100.0 \\
\hline
\end{tabular}

Ultrasound prostate size: Comparing the prostate size by ultrasound in both groups, the mean prostate volume was $46 \mathrm{cc}$ in group 1 with a standard deviation of 12.47 and $42 \mathrm{cc}$ in group 2 with a standard deviation of 14.19 .

Residual urine measurement: When we compare the residual urine in both groups, residual urine in patients in group1 was in the range of 165 $\mathrm{ml}$ and in group 2 it was in the range of $136 \mathrm{ml}$. S.creatinine at presentation: In group 1, patients who presented with elevated S.creatinine values, the following values were recorded at presentation

Figure 5 - S.creatinine in patients during presentation

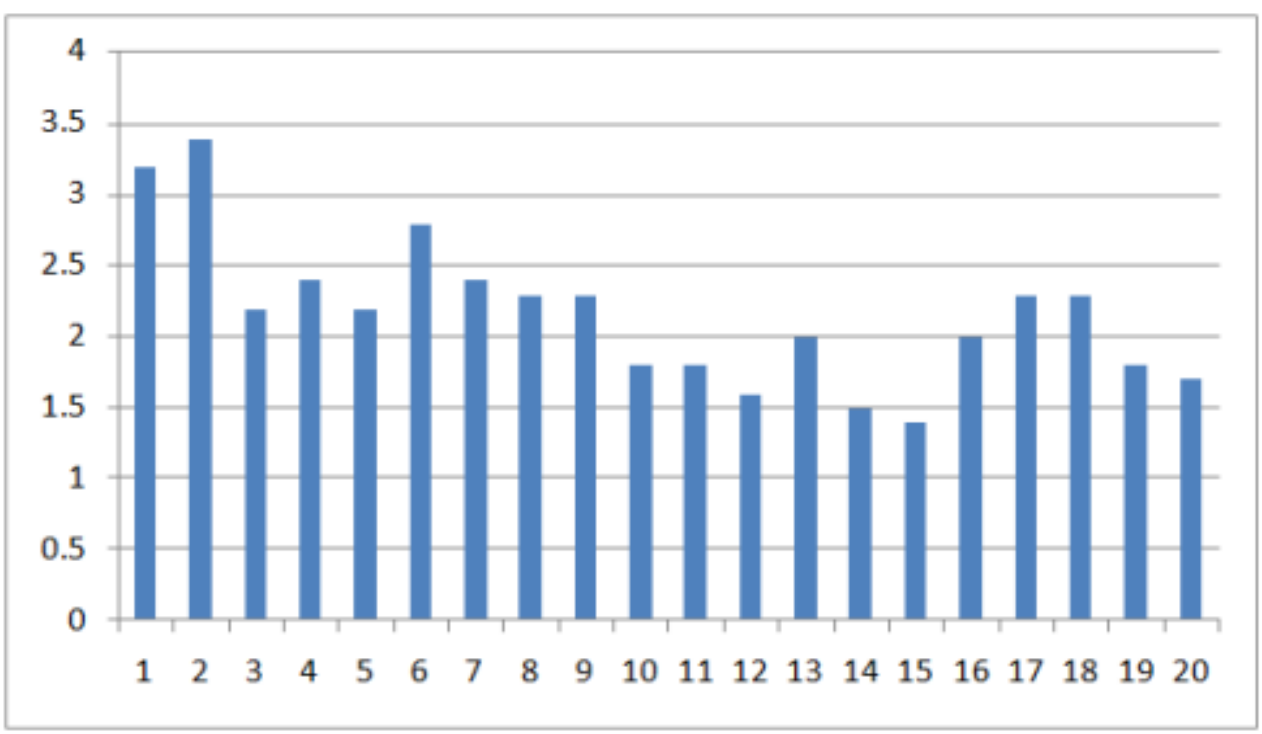

It ranged from 3.4 to 1.7 , with a mean value of 2.170 and a standard deviation of 0.5 . All these patients underwent catherization accordingly, and then their S.creatinine was recorded once it got stabilized. Whereas in group 2, the mean serum Creatinine was around 0.925 with a standard deviation of 0.1 . 


\section{JMSCR Vol||05||Issue ||10||Page 29480-29498||October}

Preoperative Serum Creatinine: Once the serum Creatinine values stabilized, the readings were recorded. Out of 20 patients who presented with elevated renal parameters, (patient with S.creatinine more than 1.4) five patients subsequently showed fall in serum Creatinine below 1.4, hence were considered along with normal patients in group 1. Because of this, the subsequent serum Creatinine values of rest of 15 patients stabilized at a mean of 1.7 with a standard deviation of 0.3 . Interestingly patients whose serum Creatinine which stabilized at a value of more than 1.4, some of them had coexistent diabetes, hypertension. This might be an explanation that these patients have developed pre-existing renal disease which was worsened by their developing benign prostatic hyperplasia.

Table 5 - Mean Creatinine levels in preoperative period

\begin{tabular}{|l|c|c|c|c|c|}
\hline & Group & $\mathrm{N}$ & Mean & Std. deviation & Std. Error Mean \\
\hline Preoperative & Group I & 15 & 1.747 & .0321 & .0780 \\
\cline { 2 - 6 } S.creatinine & Group II & 25 & .960 & .1258 & .0252 \\
\hline
\end{tabular}

Table 6 - Comparison of preoperative sodium, potassium values in both groups

\begin{tabular}{|l|c|c|c|c|c|}
\hline Pre Op Na Values & Group I & 15 & 138.13 & 1.642 & .424 \\
\hline & Group II & 25 & 138.48 & 1.711 & .342 \\
\hline Pre Op K values & Group I & 15 & 4.7 & .3327 & .0859 \\
\hline & Group II & 25 & 4.6 & .1098 & .0220 \\
\hline
\end{tabular}

As depicted above, in group 1 , the mean sodium value was 138 , whereas in group 2 , the mean sodium value was 138.48 . There was no significant difference in these two groups. Similarly, the mean preoperative potassium levels in both groups were not significantly different.

Cystourethroscopy findings of prostate and bladder in both groups

On Cystourethroscopy, out of 40 patients 16 had bilobar and 24 had trilobar enlargement.
Cystoscopy - Bladder Trabeculations: Group 1: In group 1 , out of 15,10 patients had grade 2 trabeculations, rest with grade 3 trabeculations.

Group 2: In group 2, out of 20, 17 patients had grade 2 trabeculations, rest with grade 3 trabeculations.

Resection time during surgery: The mean resection time in group 1 was 53 minutes, with a standard deviation of 8.8 minutes. In group 2 , the resection time was 56 minutes mean value with a standard deviation of 9.7 minutes.

Figure 6. Frequency distribution of complications

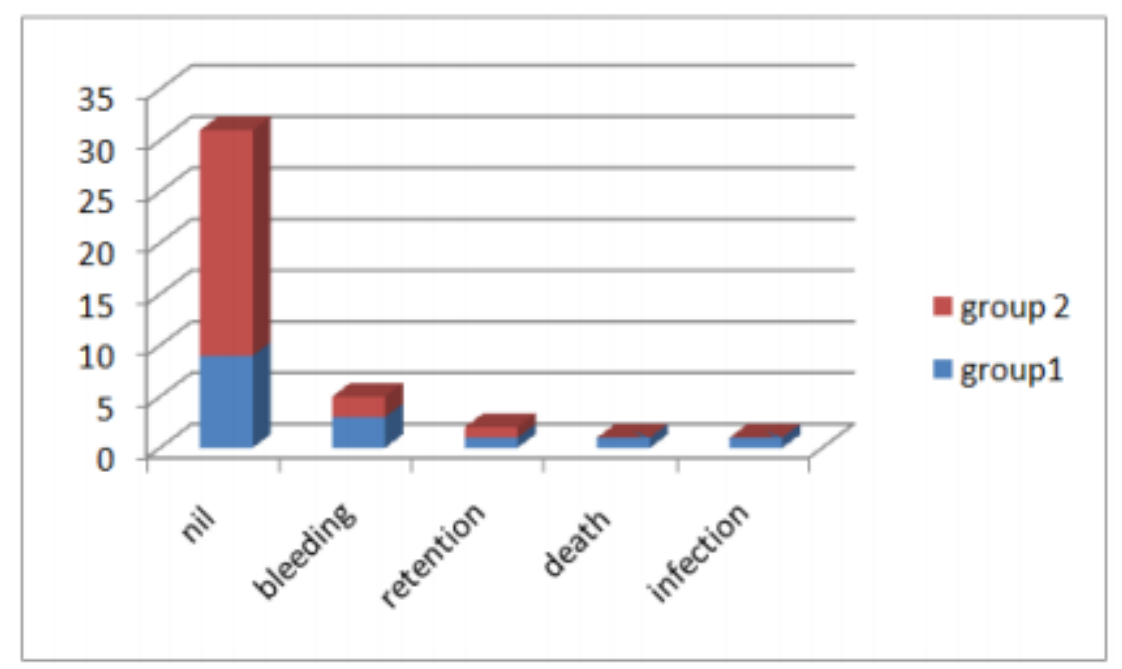




\section{JMSCR Vol||05||Issue||10||Page 29480-29498||October}

As mentioned above in group 1, out of 15 patients, three people had bleeding, one had retention, one perioperative death due to myocardial infarction was recorded, and one patient had infection. In all the patients with bleeding as complication, blood transfusion was given. Whereas in group 2, two people had bleeding out of 25 patients studied. (8\% compared to $20 \%$ in group 1). When we taken retention, three people have developed in group 2. In case of infection, none had developed, compared to one patient in renal failure group. Death was not noted in group 2, whereas one recorded in group1.

Post operative values: The mean postoperative sodium value in group 1 was 137.53 with a standard deviation of 1.995, where as in group 2 it was 137.92. So, not much of difference were noted. Similarly, post operative potassium values were in the range of 4.8 in group 1 with a standard deviation of 0.3 compared to group 2 with a mean of 4.7 .

Serum creatinine levels in group 1 post surgery: Mean serum creatinine level in group 1, which was measured at 2nd post operative day was 1.6 with a standard deviation of 0.2. Same group who had serum creatinine measured at 14 th Post operative day had a mean of 1.56 , and at 6 weeks maintained at a mean of 1.56. This shows there was a drop in serum creatinine values post surgery.

Table 7- preoperative and postoperative sodium and potassium levels in Group 1 patients

\begin{tabular}{|l|c|c|c|c|}
\hline & Mean & $\mathrm{N}$ & Std. Deviation & Std. Error Mean \\
\hline Pre op Na Values & 138 & 15 & 1.642 & .424 \\
\hline Post Op Na Values & 137 & 15 & 1.995 & .515 \\
\hline Pre Op K values & 4.7 & 15 & .3327 & .0859 \\
\hline Post Op K Values & 4.8 & 15 & .3359 & .0867 \\
\hline
\end{tabular}

As depicted in the above table the preoperative sodium and postoperative sodium in group 1, was 138 and 137.53, respectively. Similarly with potassium it was 4.6 and 4.8 respectively. When analysed with paired samples test, both of them were insignificant, meaning no significant difference in the values noted in the elevated renal parameters group.

Table 8 - Preoperative and postoperative sodium and potassium levels in Group 2 patients

\begin{tabular}{|l|c|c|c|c|c|}
\hline \multicolumn{2}{|c|}{} & Mean & $\mathrm{N}$ & Std. Deviation & Std. Error Mean \\
\hline Pair 1 & Pre op Na Values & 138 & 25 & 1.711 & .342 \\
\cline { 2 - 6 } & Post Op Na Values & 137 & 25 & 1.730 & .346 \\
\hline \multirow{2}{*}{ Pair 2 } & Pre Op K values & 4.7 & 25 & .1098 & .0220 \\
\cline { 2 - 6 } & Post Op K Values & 4.8 & 25 & .1498 & .0300 \\
\hline
\end{tabular}

Similarly, in group 2 the difference in the values in the preoperative and postoperative period was not significant.

Table 9 - Serum creatinine values post operative period and after 6 weeks post transurethral resection comparison

\begin{tabular}{|l|c|c|c|c|c|}
\hline \multicolumn{2}{|c|}{} & Mean & $\mathrm{N}$ & Std. Deviation & Std. Error Mean \\
\hline \multirow{2}{*}{ Pair 1 } & Pre Op Sr. Creatinine & 1.714 & 14 & .2852 & .0762 \\
\cline { 2 - 6 } & Sr. Creatinine at 6 wks & 1.5643 & 14 & .25603 & .06843 \\
\hline
\end{tabular}

Table 10 - Mean S.creatinine improvement in patients in preoperative period and post operative period

\begin{tabular}{|c|c|c|c|c|c|c|c|c|}
\hline & \multicolumn{5}{|c|}{ Paired Differences } & \multirow[t]{3}{*}{$\mathrm{t}$} & \multirow[t]{3}{*}{$\mathrm{df}$} & \multirow{3}{*}{$\frac{\text { Sig. }}{\text { P Value }}$} \\
\hline & MEAN & $\begin{array}{c}\text { Std. } \\
\text { Deviation }\end{array}$ & $\begin{array}{l}\text { Std Error } \\
\text { Mean }\end{array}$ & \multicolumn{2}{|c|}{$\begin{array}{l}\text { 95\% Confidence Interval } \\
\text { of the Difference }\end{array}$} & & & \\
\hline & & & & Lower & Upper & & & \\
\hline $\begin{array}{l}\text { Pre OP Sr Creatinine } \\
\text { Sr Creatinine at } 6 \mathrm{wks}\end{array}$ & .1500 & 10919 & .02918 & .0870 & .2130 & 5.140 & 13 & .000 \\
\hline
\end{tabular}

As mentioned above, the fall in serum Creatinine between the time of presentation and post operative period, was significant. This implies that transurethral resection has made a positive outcome in this group of patients. 


\section{Discussion}

In our institute it was observed that many patients who presented with obstructive Lower Urinary Tract Symptoms secondary to BPH had associated renal failure. If we have to go by the natural history of the disease progression of BPH $13.6 \%$ of patients who presented to undergo TURP were in renal failure.

Attending to high prevalence of BPH in older men with renal failure it is invaluable to take into consideration the relationship between these two clinical entities. However, despite the high prevalence of renal failure and $\mathrm{BPH}$ in elderly men, there is very limited knowledge on the association between these two conditions and it is important to discuss the relationship between $\mathrm{BPH}$ and renal failure. We decided to study the association of BPH with renal failure and role of TURP which is the gold standard surgery for BPH and its associated outcome, morbidity and mortality. A similar study determining the role of TURP in management of BPH Presenting with Renal Failure was taken up by Thomas et.al. ${ }^{55}$

In our study the mean incidence of $\mathrm{BPH}$ with renal failure was $12.5 \%$, (61/350patients) which was comparable with the other studies. The AHCPR BPH Guidelines report a mean of $13.6 \%$ of renal failure. In another study there was a reported incidence of $11 \%$ in patients with renal failure secondary to $\mathrm{BPH} .{ }^{55}$ Since renal failure is a multifactorial process making it harder to investigate the true influence of $\mathrm{BPH}$ on renal failure, the study was designed such that patients who had renal failure associated with benign hyperplasia of prostate, after excluding cases of prostatic malignancy, other causes of obstructive uropathy, as found that only 20 out of these 350 patients satisfied our inclusion criteria. In our study the average age of presentation was 65 yrs and the majority of patients in their sixth decade. Both diseases are extremely common among aging male, leading some to suggest that it is a natural concomitant of aging. ${ }^{8}$

It is known that age is an independent risk factor for renal insufficiency irrespective of medical co morbidities due to age related nephron loss and age is also risk factor for the development of BPH. Both diseases are extremely common among aging male, leading some to suggest that it is a natural concomitant of aging. ${ }^{(8)}$ There was a crosssectional association between signs and symptoms of bladder outlet obstruction and chronic kidney disease in community-dwelling men. (9) In contrast, a population-based study from Austria there was no significant association between degree of LUTS and GFR after adjusting for age in this cross sectional study. ${ }^{(10)}$ In our study severity of LUTS did affect the final outcome; however this could be confounded by other risk factors such as age, severity of renal failure, degree of bladder dysfunction etc.

More recently a cross-sectional survey in Spain of 2,000 randomly sampled men who were 50 years or older showed a $2.4 \%$ prevalence of selfreported renal failure related to a prostate condition (9\% reported renal failure from any cause). ${ }^{63,9}$ In another study, men presenting for prostate surgery had a $7.7 \%$ prevalence of renal failure compared to a $3.7 \%$ prevalence in age matched men presenting for non prostate surgery. Among patients who presented to us 15 patients $(50 \%)$ were in acute retention of urine, $30 \%$ were in chronic retention and the remaining had severe obstructive voiding symptoms.

In acute retention of urine there is rapid progression of renal failure due to defect in renal tubular function and most of the cases recover well following catheterisation unless they are in acute on chronic retention of urine where in patients take a longer time for their renal functions to recover while few cases may go into a state of refractory renal failure.

All the patients had an IPSS suggestive of severe lower urinary tract symptoms with bothersome quality of life score being unhappy and it was also observed that major contribution in their IPSS were from obstructive symptoms as compared to irritative voiding symptoms.

In $\mathrm{BPH}$, symptoms results from the direct bladder outlet obstruction (BOO) from enlarged tissue 
(static component) and the increased smooth muscle tone and resistance within the enlarged gland (dynamic component). These physiologic issues reflect in voiding dysfunctions, that significantly affects the health and quality of life of many older men.

Although signs and symptoms of BPH are normally present, there are a significant number of patients that are relatively asymptomatic (35) (without significant voiding dysfunction), but can present primarily as clinical sequel of renal insufficiency - uremia; with nausea, vomiting and mental status changes - and analytical changes electrolyte disturbances (hypercalcemia and nonanion gap acidosis).

Older patients with voiding dysfunctions caused by chronic urinary obstruction might present with hypertension due to hypervolemia in the case of bilateral obstruction or increased rennin release. Hypertension, on other hand can be itself the sole cause of renal failure. ${ }^{35}$

In our study serum creatinine (SC) and creatinine clearance ( $\mathrm{Cr} . \mathrm{Cl})$ were taken as criteria for defining renal insufficiency. Serum creatinine of $1.4 \mathrm{mg} / \mathrm{dl}$ was taken as the cut-off, a value above which was included in the study. The routine measurement of serum creatinine levels is not indicated in the initial evaluation according to the AUA Guideline Management of BPH (AUA 2010 Guidelines). This recommendation is based on the conclusion that baseline renal insufficiency appears to be no more common in men with BPH than in men of the same age group in the general population. In our study routine screening of serum creatinine not only identified patients with renal failure but also was found to be a significant risk factor for causing complication.

Coming to the comorbidities, nine patients out of 20 people enrolled under elevated renal parameters group had hypertension, diabetes or both. This was not significant when compared to the normal group.

We grouped patients with elevated renal parameters and 20 patients were enrolled into group 1. Selected patients underwent catheterisation, post catheterisation serum creatinine values settled. All our patients who came to our outpatient department underwent urinary diversion in the form of urethral catheterization, subsequently underwent TURP after stabilisation of renal functions \& once the patient was medically fit to undergo TURP. In five patients serum creatinine values normalized below 1.4, hence they were shifted to group 2 . Many of the patients presented with marginal elevation of serum creatinine indicating early renal insufficiency, this could be attributed to severity of symptoms and acute retention of urine forcing them to seek medical attention.

Following TURP the outcome and complications were analyzed. A positive outcome was defined as restoration of normal voiding pattern (as reflected by post void residual urine measurements); improvement in the renal function, and those who did not satisfy above definition were regarded as complications or negative outcome.

It was found that there was a statistically significant ( $p$ value $=0.000$ ) improvement in serum creatinine and post void residual urine in the post TURP period suggesting that TURP had a very significant role in modifying these factors.

We further analysed these factors, some patients whose serum creatinine did not touch the baseline, had comorbidites, which might suggest that the patients can have a pre-existing renal disease, which was further worsened by benign hyperplasia of prostate.

The mean prostate volume in both groups was not significantly different, both ranging from 42 to 46 cc volume. The resection time was also not very different between both groups ranging from 52-55 minutes. Mean difference in the levels of sodium, potassium were not significant in both groups in preoperative and postoperative period. No incidence of TURP syndrome was noted in our study. In our study there was no association found between volume of prostate gland with final outcome. Previous studies which examined the association between prostate size and renal function gave conflicting results ${ }^{9}$ some showing a 
strict relation between prostate size and $\mathrm{GFR}^{65}$ but other studies did not. ${ }^{66}$ Recent studies were made to relate prostate size and LUTS in BPH. Hassanzadeh et. al, ${ }^{20}$ found a significant correlation between urgency and prostate size, which can be considered as predictive factor for the disease and probably a strong link between BPE and CKD.

In other studies, it was shown that patients with BPH and renal insufficiency have much higher postoperative complications $(25 \%$ complication rate compared with $17 \%$ for patients without the condition) and mortality (up to six fold) than those with normal renal function. ${ }^{37,38,39}$ Comparing the complications between two groups, it was found that even though complications like bleeding was higher than the normal group including need for blood transfusion, they were not statistically significant. This may be attributable to the small sample size on the study point of view. The use of continuous-flow resectoscope, non hemolytic irrigation fluids and decrease in operative time, better anaesthetic care due to improving and refining of TURP technique in time with the increased number of operations performed probably has had significant positive effects on TURP outcomes. This leads to a decrease in complication rate compared to older studies. Death was seen in the elevated renal parameter group, none was recorded in group 2. Death in this patient had been due to myocardial infarction. Renal failure patients are prone for cardiovascular complications

In our study there was no association found between amounts of residual urine with final outcome. For years it has been well described that large volumes (»300 mL) affect renal function in advanced $\mathrm{BPH} .{ }^{24,9,12}$ Recent studies, however, demonstrate that the volume of residual urine (post void) necessary to impair renal function is not that elevated.

\section{Limitations of this Study}

Sample size in the elevated parameters group who underwent transurethral resection of prostate is less, which was further reduced by patients attaining normalization of creatinine values post catheterization who subsequently got shifted to group 2.

This study was conducted in a group of patients with lesser grades of chronic kidney disease, thereby excluding patients with higher grades of chronic kidney disease and patients on dialysis. To exactly study the impact of transurethral resection and its complications in these important subgroups of patients also becomes important.

All the patients who underwent transurethral resection, procedure was not done by a single surgeon. As it is a teaching institute, variations in technique and time varied between individual surgeons.

The fourth limitation was following up. It was hard to get follow up of patients, who often faltered on timely visits to hospital despite reminders.

\section{Conclusion}

The incidence of renal failure associated with benign prostatic hyperplasia in our study was about $12.5 \%$. After excluding patients with prostatic malignancy, patients needing dialysis, the study group constituted $5 \%$.

The age of presentation was around 64-65 years, which also coincided with increased prevalence of chronic kidney disease in elderly population, who also present with benign hyperplasia of prostate.

There was no significant variation in preoperative and postoperative levels of serum sodium, potassium levels in patients with nondialysis requiring renal failure (S.creatinine less than 3), when compared to normal patients.

Complications of transurethral resection in patients who had nondialysis requiring renal failure, was on the higher side. Bleeding as a complication requiring blood transfusion was noted in $20 \%$ of patients compared to normal patients. But overall complication rate was not statistically significant. This can be attributed either small sample size. Improvement in instruments like bipolar resection, use of non 
hemolytic irrigation solutions, better anaesthetic care can be a factor.

The outcome following TURP was successful with restoration in normal renal function and normal voiding pattern in majority of patients and it was further noted that the successful outcome of TURP in these patients were influenced by various factors such as age, duration of symptoms, severity of lower urinary tract symptoms, severity of renal failure at the time of presentation. The size of Prostate gland had no correlation with the final outcome.

\section{Bibliography}

1. Arrighi HM, Metter EJ, Guess HA, Fozzard JL. Natural history of benign prostatic hyperplasia and risk of prostatectomy. The Baltimore Longitudinal Study of Aging. Urology. 1991; 38(1 Suppl): p. 4-8.

2. Kumar R, Hill CM, McGeown MG. Acute renal failure in the elderly. Lancet. 1973 Jan; 1(7794): p. 90-91.

3. Wein A. campbell-walsh urology Wein AJ, editor.: elsevier; 2012.

4. Berry SJ, Coffey DS, Walsh PC, Ewing LL. The development of human benign prostatic hyperplasia with age. J Urol. 1984 Sep; 132(3): p. 474-479.

5. Nielsen KK, Nordling J, Hald T. Critical review of the diagnosis of prostatic obstruction. Neurourol Urodyn. 1994; 13(3): p. 201- 217.

6. Abrams P. LUTS, BPH, BPE, BPO: A Plea for the Logical Use of Correct Terms. Rev Urol. 1999; 1(2): p. 65.

7. Rosen R, Altwein J, Boyle P, Kirby RS, Lukacs B, Meuleman E, et al. Lower urinary tract symptoms and male sexual dysfunction: the multinational survey of the aging male (MSAM-7). Eur Urol. 2003 Dec; 44(6): p. 637-649.

8. Wu Sl, Li Nc, Xiao Yx, Jin J, Qiu Sp, Ye $\mathrm{Zq}$, et al. Natural history of benign prostate hyperplasia. Chin Med J (Engl). 2006 Dec; 119(24): p. 2085-2089.

9. Rule AD, Jacobson DJ, Roberts RO, Girman CJ, McGree ME, Lieber MM, et al. The association between benign prostatic hyperplasia and chronic kidney disease in community-dwelling men. Kidney Int. 2005 Jun; 67(6): p. 2376-2382.

10. Ponholzer A, Temml C, Obermayr RP, Rauchenwald M, Madersbacher S. The association between lower urinary tract symptoms and renal function in men: a cross-sectional and 5-year longitudinal analysis. J Urol. 2006 Apr; 175(4): p. 1398-1402.

11. Hallan SI, Kwong D, Vikse BE, Stevens P. Use of a prostate symptom score to identify men at risk of future kidney failure: insights from the HUNT II Study. Am J Kidney Dis. 2010 Sep; 56(3): p. 477485.

12. Yamasaki T, Naganuma T, Iguchi $T$, Kuroki Y, Kuwabara N, Takemoto Y, et al. Association between chronic kidney disease and small residual urine volumes in patients with benign prostatic hyperplasia. Nephrology (Carlton). 2011 Mar; 16(3): p. 335-339.

13. Hong SK, Lee ST, Jeong SJ, Byun SS, Hong YK, Park DS, et al. Chronic kidney disease among men with lower urinary tract symptoms due to benign prostatic hyperplasia. BJU Int. 2010 May; 105(10): p. 1424-1428.

14. Oesterling JE. Benign prostatic hyperplasia: a review of its histogenesis and natural history. Prostate Suppl. 1996; 6: p. $67-73$.

15. Coroneos E, Assouad M, Krishnan B, Truong LD. Urinary obstruction causes irreversible renal failure by inducing chronic tubulointerstitial nephritis. Clin Nephrol. 1997 Aug; 48(2): p. 125-128. 
16. McNeal JE. Origin and evolution of benign prostatic enlargement. Invest Urol. 1978 Jan; 15(4): p. 340-345.

17. Lin VK, Robertson JB, Lee IL, Zimmern PE, McConnell JD. Smooth muscle myosin heavy chains are developmentally regulated in the rabbit bladder. J Urol. 2000 Oct; 164(4): p. 1376-1380.

18. Schwinn DA. Adrenergic receptors: unique localization in human tissues. Adv Pharmacol. 1994; 31: p. 333-341.

19. Boesch ST, Dobler G, Ramoner R, Corvin S, Thurnher M, Bartsch G, et al. Effects of alpha1-adrenoceptor antagonists on cultured prostatic smooth muscle cells. Prostate Suppl. 2000; 9: p. 34-41.

20. Hassanzadeh K, Yavari-kia P, AhmadiAsrbadr Y, Nader-Abbasi F. Nonobstructive lower urinary tract symptoms versus prostate volume in benign prostatic hyperplasia. Pak J Biol Sci. 2010 Dec; 13(23): p. 1129-1134.

21. Hill AM, Philpott N, Kay JD, Smith JC, Fellows GJ, Sacks SH. Prevalence and outcome of renal impairment at prostatectomy. Br J Urol. 1993 Apr; 71(4): p. 464-468.

22. Hong SJ, Rayford W, Valiquette L, Emberton M. The importance of patient perception in the clinical assessment of benign prostatic hyperplasia and its management. BJU Int. 2005 Jan; 95(1): p. 15-19.

23. Sacks SH, Aparicio SA, Bevan A, Oliver DO, Will EJ, Davison AM. Late renal failure due to prostatic outflow obstruction: a preventable disease. BMJ. 1989 Jan; 298(6667): p. 156-159

24. Styles RA, Ramsden PD, Neal DE. The outcome of prostatectomy on chronic retention of urine. J Urol. 1991 Oct; 146(4): p. 1029- 1033.

25. Prakash J, Saxena RK, Sharma OP, Usha. Spectrum of renal diseases in the elderly: single center experience from a developing country. Int Urol Nephrol. 2001; 33(2): p. 227-233.

26. Jones DA, Gilpin SA, Holden D, Dixon JS, O'Reilly PH, George NJ. Relationship between bladder morphology and longterm outcome of treatment in patients with high pressure chronic retention of urine. $\mathrm{Br}$ J Urol. 1991 Mar; 67(3): p. 280-285.

27. Gosling JA, Dixon JS. Structure of trabeculated detrusor smooth muscle in cases of prostatic hypertrophy. Urol Int. 1980; 35(5): p. 351-355.

28. Comiter CV, Sullivan MP, Schacterle RS, Cohen LH, Valla SV. Urodynamic risk factors for renal dysfunction in men with obstructive and nonobstructive voiding dysfunction. J Urol. 1997 Jul; 158(1): p. 181-185.

29. Jones SA, Ellis JR, Klegeris A, Greenfield SA. The relationship between visual stimulation, behaviour and continuous release of protein in the substantia nigra. Brain Res. 1991 Sep; 560(1-2): p. 163166.

30. Ghose RR, Harindra V. Unrecognised high pressure chronic retention of urine presenting with systemic arterial hypertension. BMJ. 1989 Jun; 298(6688): p. 1626-1628.

31. Klahr S. Urinary tract obstruction. Semin Nephrol. 2001 Mar; 21(2): p. 133-145.

32. Gerber GS, Goldfischer ER, Karrison TG, Bales GT. Serum creatinine measurements in men with lower urinary tract symptoms secondary to benign prostatic hyperplasia. Urology. 1997 May; 49(5): p. 697-702.

33. Jacobsen SJ, Guess HA, Panser L, Girman CJ, Chute CG, Oesterling JE, et al. A population-based study of health careseeking behavior for treatment of urinary symptoms. The Olmsted County Study of Urinary Symptoms and Health Status Among Men. Arch Fam Med. 1993 Jul; 2(7): p. 729-735. 
34. Neal DE. Irreversible renal failure in men with outflow obstruction: is it a preventable disease? Postgrad Med J. 1990 Dec; 66(782): p. 996-999.

35. Tseng TY, Stoller ML. Obstructive uropathy. Clin Geriatr Med. 2009 Aug; 25(3): p. 437-443.

36. Cockett AT, Barry MJ, Holtgrewe HL, Sihelnick S, Williams R, McConnell J. Indications for treatment of benign prostatic hyperplasia. The American Urological Association Study. Cancer. 1992 Jul; 70(1 Suppl): p. 280-283.

37. HOLTGREWE HL, VALK WL. Factors influencing the mortality and morbidity of transurethral prostatectomy: a study of 2,015 cases. J Urol. 1962 Mar; 87: p. 450459.

38. Melchior J, Valk WL, Foret JD, Mebust WK. Transurethral prostatectomy in the azotemic patient. J Urol. 1974 Nov; 112(5): p. 643-646.

39. Mebust WK, Holtgrewe HL, Cockett AT, Peters PC, WCtAUA. Transurethral prostatectomy: immediate and postoperative complications. Cooperative study of 13 participating institutions evaluating 3,885 patients. J Urol, 141: 243-247, 1989. J Urol. 2002 Jan; 167(1): p. 5-9.

40. McConnell JD, Barry MJ, Bruskewitz RC. Benign prostatic hyperplasia: diagnosis and treatment. Agency for Health Care Policy and Research. Clin Pract Guidel Quick Ref Guide Clin. 1994 Feb;(8): p. 117.

41. McConnell JD, Barry MJ, Bruskewitz RC. Benign prostatic hyperplasia: diagnosis and treatment. Agency for Health Care Policy and Research. Clin Pract Guidel Quick Ref Guide Clin. 1994 Feb;(8): p. 117.

42. McConnell JD, Bruskewitz R, Walsh P, Andriole G, Lieber M, Holtgrewe HL, et al. The effect of finasteride on the risk of acute urinary retention and the need for surgical treatment among men with benign prostatic hyperplasia. Finasteride LongTerm Efficacy and Safety Study Group. N Engl J Med. 1998 Feb; 338(9): p. 557-563.

43. Barry MJ, Fowler JF, O'Leary MP, Bruskewitz RC, Holtgrewe HL, Mebust $\mathrm{WK}$, et al. The American Urological Association symptom index for benign prostatic hyperplasia. The Measurement Committee of the American Urological Association. J Urol. 1992 Nov; 148(5): p. 1549--57; discussion 1564.

44. Hong SK, Oh JJ, Jeong SJ, Jeong CW, Kim IS, Park JM, et al. Prediction of outcomes after radical prostatectomy in patients diagnosed with prostate cancer of biopsy Gleason score $\geq 8$ via contemporary multi $(\geq 12)$-core prostate biopsy. BJU Int. 2011 Jul; 108(2): p. 217222.

45. Mebust WK, Holtgrewe HL, Cockett AT, Peters PC. Transurethral prostatectomy: immediate and postoperative complications. A cooperative study of 13 participating institutions evaluating 3,885 patients. J Urol. 1989 Feb; 141(2): p. 243247.

46. Roehrborn CG. BPH progression: concept and key learning from MTOPS, ALTESS, COMBAT, and ALF-ONE. BJU Int. 2008 Mar; 101 Suppl 3: p. 17-21.

47. Koch WF, Debruyne FM,. The outcome of renal ultrasound in the assessment of 556 consecutive patients with benign prostatic hyperplasia. J Urol. 1996 Jan; 155(1): p. 186-189.

48. Sutaria PM, Staskin DR. Hydronephrosis and renal deterioration in the elderly due to abnormalities of the lower urinary tract and ureterovesical junction. Int Urol Nephrol. 2000; 32(1): p. 119-126.

49. Kojima M, Inui E, Ochiai A, Naya Y, Ukimura $\mathrm{O}$, Watanabe $\mathrm{H}$. Noninvasive quantitative estimation of infravesical obstruction using ultrasonic measurement 
of bladder weight. J Urol. 1997 Feb; 157(2): p. 476-479.

50. Gabuev A, Oelke M. [Latest trends and recommendations on epidemiology, diagnosis, and treatment of benign prostatic hyperplasia (BPH)]. Aktuelle Urol. 2011 May; 42(3): p. 167-178.

51. Neal DE, Styles RA, Powell PH, Ramsden PD. Relationship between detrusor function and residual urine in men undergoing prostatectomy. Br J Urol. 1987 Dec; 60(6): p. 560-566.

52. Meigs JB, Mohr B, Barry MJ, Collins MM, McKinlay JB. Risk factors for clinical benign prostatic hyperplasia in a communitybased population of healthy aging men. J Clin Epidemiol. 2001 Sep; 54(9): p. 935-944.

53. Emberton M, Andriole GL, Djavan B, Hoefner $\mathrm{K}$, et al. Benign prostatic hyperplasia: a progressive disease of aging men. Urology. 2003 Feb; 61(2): p. 267273.

54. Flanigan RC, Reda DJ, Wasson JH, Anderson RJ, Abdellatif M, Bruskewitz RC. 5-year outcome of surgical resection and watchful waiting for men with moderately symptomatic benign prostatic hyperplasia: a Department of Veterans Affairs cooperative study. J Urol. 1998 Jul; 160(1): p. 12--6; discussion 16-7.

55. Thomas AZ, Thomas AA, Conlon P, Hickey D, Little DM. Benign prostatic hyperplasia presenting with renal failure-what is the role for transurethral resection of the prostate (TURP)? Ir Med J. 2009 Feb; 102(2): p. 43-44.

56. Rassweiler J, Teber D, Kuntz R, Hofmann $\mathrm{R}$. Complications of transurethral resection of the prostate (TURP)--incidence, management, and prevention. Eur Urol. 2006 Nov; 50(5): p. 969--79; discussion 980.

57. Borboroglu PG, Kane CJ, Ward JF, Roberts JL, Sands JP. Immediate and postoperative complications of transurethral prostatectomy in the 1990s. J Urol. 1999 Oct; 162(4): p. 1307-1310.

58. Wendt-Nordahl G, Häcker A, Reich O, Djavan B, Alken P, Michel MS. The Vista system: a new bipolar resection device for endourological procedures: comparison with conventional resectoscope. Eur Urol. 2004 Nov; 46(5): p. 586-590.

59. Schatzl G, Madersbacher S, Djavan B, Lang T, Marberger M. Two-year results of transurethral resection of the prostate versus four 'less invasive' treatment options. Eur Urol. 2000 Jun; 37(6): p. 695701.

60. Berger AP, Wirtenberger W, Bektic J, Steiner H, Spranger R, Bartsch G, et al. Safer transurethral resection of the prostate: coagulating intermittent cutting reduces hemostatic complications. J Urol. 2004 Jan; 171(1): p. 289-291.

61. McAfee JG, Singh A, O'Callaghan JP. Nuclear imaging supplementary to urography in obstructive uropathy. Radiology. 1980 Nov; 137(2): p. 487-496.

62. Green J, Vardy Y, Munichor M, Better OS. Extreme unilateral hydronephrosis with normal glomerular filtration rate: physiological studies in a case of obstructive uropathy. J Urol. 1986 Aug; 136(2): p. 361-365.

63. Hunter DJ, Berra-Unamuno A, MartinGordo A. Prevalence of urinary symptoms and other urological conditions in Spanish men 50 years old or older. J Urol. 1996 Jun; 155(6): p. 1965-1970.

64. Jacobsen SJ, Girman CJ, Lieber MM. Natural history of benign prostatic hyperplasia. Urology. 2001 Dec; 58(6 Suppl 1): p. 5--16; discussion 16.

65. OLBRICH O, WOODFORD-WILLIAMS E, IRVINE RE, WEBSTER D. Renal function in prostatism. Lancet. 1957 Jun; 272(6983): p. 1322-1324.

66. Terris MK, Afzal N, Kabalin JN. Correlation of transrectal ultrasound 
measurements of prostate and transition zone size with symptom score, bother score, urinary flow rate, and post-void residual volume. Urology. 1998 Sep; 52(3): p. 462-466.

67. Camici M, Sagripanti A. [Uremic coagulopathy. Role of thrombin]. Minerva Urol Nefrol. 2000 Jun; 52(2): p. 67-72.

68. Christ GJ, Liebert M. Proceedings of the Baltimore smooth muscle meeting: identifying research frontiers and priorities for the lower urinary tract. J Urol. 2005 Apr; 173(4): p. 1406-1409.

69. McVary KT. BPH: epidemiology and comorbidities. Am J Manag Care. 2006 Apr; 12(5 Suppl): p. S122--S128.

70. Alp Ozgur Akdemir, Cetin Volkan Oztekin, Omer Gokhan Doluoglu. Effects of Transurethral resection of prostate on morbidity and mortality in patients with nondialysis- requiring renal insufficiency. Ther Adv Urol.2012 Apr; 4(2):51-56. 